\title{
An Australian Case Study of Mandatory Education for the Bus and Coach Industry
}

Samantha Y. Taylor, Institute of Transport Studies, Monash University Kenneth J. Button, School of Public Policy, George Mason University

\section{Abstract}

The changing regulatory environment in which public transportation is provided has generated a need for different forms of bus operations and management. This article discusses the introduction and development of a compulsory education program for bus and coach operators in Victoria, Australia. The Victorian government introduced a new system of operator (manager or owner in U.S. terminology) accreditation through the Public Transport Competition Regulations (1999). The accreditation process requires individual managers and owners to successfully complete the transport management course in bus and coach operations.

The development and introduction of the course is a significant change for the industry and exists in a challenging sociopolitical environment. The course is designed to help people make the best use of new opportunities, such as open entry and competition promoted by the legislation. The majority of operators who have already completed the course found it extremely helpful, useful, and enjoyable. On the other hand, a "fear of the unknown" for some operators has resulted in resentment and aggression in a few cases. The article describes the challenges of working with operators as they move away from a protected environment toward accreditation. 


\section{Introduction}

During the past 20 years, major changes have taken place throughout the world in the area of transportation public policy. In virtually all cases, there has been a marked liberalization of policy. In addition to major deregulation and privatization, significant shifts also have occurred in the ways that remaining areas of regulations are applied.

In April 1995, the Australian Commonwealth, states, and territories agreed to the implementation of the National Competition Policy. This policy states that legislation should not restrict competition, unless it can be demonstrated that restricted competition is to the benefit of the public. Under this principle, the government of the State of Victoria introduced the Public Transport Competition Act in 1995 to provide the legislative framework for fundamental changes in the way bus and coach services are provided.

As a consequence of this act and the Public Transport Competition Regulations (1999),' the bus industry has moved from a vehicle-based licensing system to mandatory accreditation. The old system was based on an operator's ability to secure vehicle licenses, thus giving a vehicle, rather than a person, specific rights to a service type. The new system eliminates the need for vehicle licenses, and requires an individual manager or owner to be accredited by satisfying certain conditions, one of which is the successful completion of an approved education program in transport management. ${ }^{2}$

The Victorian government contracted with the Institute of Transport Studies at Monash University (located near Melbourne, the state capital of Victoria) to act as service provider and develop an approved education program in consultation with the bus industry. The initial aims were to develop a course that:

- improves bus operators' understanding of legislation concerning safety, maintenance, and service obligations under the Public Transport Competition Regulations (1999);

- achieves reciprocity with other states' training requirements, with the ultimate aim of having the course recognized nationally; and

- provides specific knowledge and skills applicable to the bus and coach industry based on industry best practice. 
The Victorian bus and coach industry is represented by the Bus Association Victoria (BAV). The association was established in Victoria in 1950, during the growth period after World War II, and has since been involved in negotiations with government regarding private passenger services. The $\mathrm{BAV}$ is a powerful force in the bus and coach industry, presently representing over 95 percent of the operators. The association supported the introduction of accreditation and the transport management course, in the belief that it would strengthen the industry.

While most operators view the provision of education as a major step forward and an opportunity for advancement, there are a few who are threatened by its introduction. Many owners and managers have not experienced formal education since elementary school, having learned their skills over decades on the job. The majority rely heavily on the BAV for information and assistance in interpreting legislation, negotiating with the government, reducing competition, and handling legal matters such as unfair dismissal. In many cases, operators, particularly those located in remote areas, view the prospect of study with trepidation and resentment.

This article is based on pragmatic experience and describes the curriculum development and sociopolitical processes of implementing a mandatory educational course. It describes the regulatory framework for bus and coach operations, both past and present, and defines the different operation categories in use today. It also examines course subjects, the development process, and the unique demands of distance education. The article concludes with a description of the issues and challenges of mandatory education, emphasizing the relevant sociopolitical complexities.

\section{Background}

This section examines the regulatory framework for the compulsory education program.

\section{The Old System of Vehicle-Based Licensing}

Prior to the introduction of the Public Transport Competition Regulations, entry into the bus and coach industry was by way of a specific vehicle license. ${ }^{3}$ 
Under this system, individual operators had rights to provide certain types of services. Each type of operation was allocated a license category. Over time, the parameters originally assigned to particular operations were found to be too narrow and the industry demanded that new categories be created. Eventually, 16 different license types evolved for passenger vehicles and 11 license types for bus operations. The system had become overly complicated and restrictive and was seen as contrary to national competition policy.

The Victorian State parliamentary authorization of the Public Transport Competition Regulations in May 1999 allowed the old licensing categories to be streamlined to five new, simple and less-restrictive categories. Table 1 presents the categories as well as the relevant operational criteria for each service category. The transport management course addresses scheduled and nonscheduled passenger services only.

\section{The New System of Accreditation}

Consistent with the principles of National Competition Policy, the Public Transport Competition Act of 1995 established a legislative framework to promote commercialization of public transport operations in Victoria. The new legislation relates to bus and coach operators of regular passenger services (including route, school contract, and long-distance services) and tour and charter services. Although the act also requires the operators of hire and drive, private omnibuses, and courtesy buses (having a seating capacity of more than 12 passenger seats) to be accredited, the exact requirements have not been determined.

The main purpose of the act is to improve road-based public transport operations through operator accreditation and implement service contracts for particular types of transport (e.g., route or school bus services). Service contracts are agreements between an operator and the Victorian State government (Department of Infrastructure) to operate country route, metropolitan route, or school bus services. A condition of a service agreement or contract is that accreditation is maintained.

This change in regulatory style relaxes restrictions within the industry and provides greater flexibility for operators. Potentially, operators will be quali- 


\section{Table 1}

\section{Categories of Operation Used by the Department of Infrastructure}

Accreditation Category

Scheduled passenger service

Nonscheduled passenger service

Courtesy bus service

Private bus service

Hire and drive
Operational Criteria

- Operated for hire or reward

- Available to the general public

- Operated to a timetable or within a specified area on a regular basis along a route that varies in accordance with passenger demands

- May or may not operate under a service contract with the Department of Infrastructure

- Operated for hire or reward

- Available to the general public

- Chartered to carry a person or party to a destination specified by the hirer or offered by the operator

- Passengers charged as a group or at separate and distinct fares

- May operate on an itinerary but not as a scheduled passenger service

- Provided by a business free of charge to its customers or employees

- Not available to the general public

- Service is merely an adjunct to the core business

- Operated by a religious, philanthropic, educational, sporting, or social body for the benefit and carriage of its members exclusively

- Used in connection with the activities of the organization

- Not operated for hire or reward

- Not available to the general public

- Hired for reward or valuable consideration for a finite period

- Driven by the hirer or a person on behalf of the hirer

- Available to the general public

Source: Public Transport Safety Directorate, 1999.

fied to tender for a wider range of services without going through the lengthy license application process for each vehicle they acquire and for each service. The new "person-based" system of accreditation is simpler and more flexible, and is based on an operator's ability to run services, rather than the ability to obtain specific vehicle license types. In the past, a license application was gazetted for 28 days, during which time objections could be lodged. On the basis of these objections, a license could be refused. Using defined standards 
of transport management and education, the new legislation aims to ensure a satisfactory standard of safety and service to the traveling public while allowing flexibility in ensuring vehicle safety and driver performance.

The act states that an accredited person will have the ability to provide road transport passenger services; manage transport business operations; provide the required standard of safety and service to passengers and the public; and provide the required standard of vehicles and equipment, including design, service, maintenance, and condition. At least one person in each business operation is required to complete the transport management course. Usually, this individual is responsible for the bus and coach operation.

The detailed mechanisms enabling the act's initiatives to be implemented are contained in the Public Transport Competition Regulations (1999). The regulations list the legal conditions an accredited person must satisfy and maintain on behalf of the operation, including an emergency management plan, vehicle maintenance system, driver monitoring procedures, accident register, public complaints register, and mobility enhancement strategy (which relates to access for disabled customers). For most operators, the conditions reflect existing best practice within the industry and are not considered unduly onerous. However, they do require an operator to follow documentation processes and exhibit effective organization and administration skills.

\section{Popular Definitions for Service Types}

For purposes of this article, the following common definitions are used:

- Regular passenger service: A road transport passenger service operated along a fixed route on a regular basis (includes route, school contract, and long-distance services).

- Route service: A road transport passenger service operated along a fixed route on a regular timetable.

- School service: An approved road transport passenger service operated along a fixed route on a regular timetable (morning and afternoon) for the purposes of transporting students to and from school.

- Tour: A road transport journey (usually for an extended period of time) to places of interest including provision of sustenance, accommodation, and organized activities. 
- Charter: A commercial passenger vehicle (including driver) for hire. This potentially encompasses trips for sporting clubs and social groups; temporary replacement services such as school services, fixed-route services, or services for special events; and transport for preorganized tours.

A number of different definitions exist in the various transport-related acts and regulations. These can be confusing to operators, regulators, and transport professionals trying to untangle the web of definitions. In the future, it is expected that common usage will comprise the definitions and terminology given in Table 1.

\section{Transport Management Course Structure}

While the changes in legislation have been initiated by a change in government ideology, the Victorian bus industry has been supportive of an educational course for some time. This follows industry support for the development of a transport management course at the Institute of Transport Studies in Sydney (New South Wales), which began in the early 1990s. The Victorian course is based on the New South Wales course but has been altered to suit distance education, Victorian legislation, and Victorian operations.

\section{Course Materials and Subjects}

The guided course materials are provided in the form of printed notes. While some operators have access to computers and the Internet, the majority do not. The notes contain introductory information on the course development process and authors, subject format, exam (or assignment), and advice on how to study.

Based on discussions with the BAV, it was decided to offer seven subjects over a period of one to two years. The association expressed concern for small operators approaching retirement age and the stress on these individuals to complete the course. These operators were placed in a special category by virtue of the fact that they were owner-drivers, often farmers (so had another source of income), had left school at a very young age, and were close to or past retirement age (one student was 88 years old). Consequently, a subject containing the "bare essentials" for operators who have a small number of buses, operate school services, do not undertake significant charter, ${ }^{4}$ and are not planning to expand their business is provided in subject 2101 . 
In addition to those operators looking to retire, the industry is preparing for the introduction of contract payments, paid by the government and based on patronage levels. The more passengers an operator carries, the greater the incentive payment. Hence, operators will be encouraged to gain knowledge about their markets as well as plan and promote their services accordingly. The aim of the full transport management program (subjects 3101,3102, 3103, and 3104 ) is to teach an understanding of marketing principles, how to critically evaluate services, and how to achieve effective financial management of costs and income. Students will also gain knowledge in the areas of human resource management and interpersonal communication skills.

Subject 2101-Introduction to Bus and Coach Operations: Small (School Bus) Operators. This subject covers the fundamentals of operation in terms of various legal and ethical requirements. The many acts, regulations, and government documents essential to running bus and coach businesses are discussed. Information on accreditation conditions relating to management information systems, vehicle maintenance systems, vehicle standards, and other conditions for accreditation are also presented. In addition, this subject examines requirements for occupational health and safety, environmental standards, and ethics within the industry.

To complete this subject, students are strongly advised to purchase legislative documents, which are fundamental to operating a bus and coach business. Interestingly, most operators rely on the BAV for legislative information and amendments rather than the source. The association's materials may not be comprehensive in coverage or germane to the operator's particular needs. From a course-provider perspective, operators have a responsibility to know where to find this information.

Subject 3101-Introduction to Bus and Coach Operations: Legislation, Safety, and Maintenance. Generally, the content for this course is similar to that covered in subject 2101, with the exception that this subject has a longer exam that tests the application of knowledge through a case study.

Subject 3102-Financial Management. Financial management assists operators in understanding the financial position and risks of their business. 
This subject introduces key accounting concepts, which form the basis of financial understanding and business understanding. It examines charts of accounts and profit and loss statements and discusses management accounting (the method used to analyze data against prior years and financial benchmarks), thus showing students how to evaluate business performance. Financial and nonfinancial techniques to analyze business processes and prospective business opportunities are also presented.

Subject 3103-Marketing, Planning, and Operations. This subject discusses the actual operation of passenger services. Operators are required to choose one of the following subjects depending on the category of accreditation they wish to obtain. The operator's choice depends on the level of accreditation they wish to qualify for; that is, scheduled passenger services, nonscheduled passenger services, or both (Table 1). For example, a tour operator is required to complete subject $3103 \mathrm{C}$, while a route operator would need to complete subject 3103B.

3103A-Bus and Coach Operations. This subject brings together the essential components of running a charter, school, route, and tour service and includes discussion of resource utilization and administration. Survey methods to assist operators in understanding passenger and nonpassenger markets are explained. Advanced technologies with potential applications to bus and coach services are discussed as well as service design and planning. The subject provides guidance on packaging and marketing tours and examines factors that affect tourism. Travel agents legislation is also discussed.

$3103 B-B$-BS Operations. This area combines the essential components of running a charter, school, or route service in one subject and includes discussion of resource utilization and administration. Survey methods to assist operators in understanding passenger and nonpassenger markets are explained. Advanced technologies with potential applications to bus and coach services are explored as well as service design and planning.

3103C - Coach Operations. The essential components of tour operations are presented in this study. Discussions focus on resource utilization and administration. Survey methods to assist operators in understanding passenger 
and nonpassenger markets are explained. The subject includes advice on packaging and marketing tours and some explanation of the factors that affect tourism. Travel agents legislation is also discussed.

Potentially, charter operators can deliver a very wide range of services and therefore need to be educated or qualified to an appropriate standard. This is an important change, which has occurred as a result of the new legislation. In the past, charter operators could not tender for school or route services, or run tours, due to restrictions imposed by a vehicle's license category. Now, if charter operators complete the transport management course for bus and coach operations, they are legally entitled to bid for any service.

Subject 3104-Human Resources. This subject provides an overview of the fundamentals of human resource management to help foster productive working relationships and good customer relations. In this course, students examine different styles of management and practice the communication skills of negotiating, listening, and questioning. Position descriptions, induction, performance management, training, remuneration, and the policies necessary for maintaining an effective and cohesive workplace are discussed. Industrial relations and enterprise bargaining are also explained.

\section{Recognition of Prior Study}

Consistent with the opportunity to gain an exemption from the course through interstate reciprocity, individuals have an opportunity to gain credit for one or more subjects through prior study. However, it is unlikely that a student will receive credit for the legislation-based subject (2101 or 3101) because legislation was enacted only recently, or for the marketing, planning, and operations subject (3103) due to the specificity of the subject material. The most likely subject for credit is human resources (3104). The financial management subject (3102) is a possibility, though unlikely because it emphasizes a specific application of financial management principles to the bus industry, which is unlikely to have been taught in generalist accounting courses. The subject emphasizes the application of accounting principles. For example, it considers costing routes (drivers, dead running, number of buses, alterations to routes, timetable frequency, etc.) and trade-offs between route design and costs. This is not taught in tra- 
ditional accounting courses and is important in terms of bringing the industry to a standard where best practice is used to determine costs.

Recognition of prior study may be granted if the student can demonstrate that the objectives of a subject have already been met. To apply for recognition of prior study, students are required to submit a written case, demonstrating how they have achieved the course objectives through prior study, and present copies of relevant documentation to the university.

\section{Course Development}

During the course development process, regular discussions were held with the Victorian Department of Infrastructure (formerly the Department of Transport) and the BAV. The Department of Infrastructure provided necessary input on legislation aspects relevant to the course, and various members of the BAV contributed to operational components.

One of the challenges in course development was reflecting each segment of the industry (metropolitan, rural, school service, route service, tour, and charter). While one might presume timetable operations to be mainstream knowledge for operators, some operators see it quite differently and want a course that reflects their specific idiosyncratic operations. Achieving balance in course content is and will continue to be a challenge.

Course development is further complicated by the fact that the program is mandatory. Change is considerably threatening to many of these operators, especially those who have not been to school since early adolescence. Accordingly, it is important that care be taken in explaining the expectations and structure of the course in order to alleviate concerns.

The course was tested in 1998 using a pilot of 30 operators. Feedback from this program suggested that an introductory session be given at the beginning of each semester to familiarize students with university staff (the faces to the names) and to explain the requirements of each subject. To date, the introductory sessions have been based at the fundamental level and concentrated on the legislation subject (subject 2101 or 3101) and the financial management subject (3102). Members of the BAV are invited to talk on an aspect of the course and past students are invited to present their course-related experiences. 
Due to the fact that many operators, especially small operators, are nervous and fearful of the unknown when they enroll in the course, much of the familiarization session is designed to encourage a positive mental attitude.

Although the course is tailored to the bus industry and there was significant industry pressure to ensure maximum flexibility in the course, consistency in due dates and student correspondence help develop a sense of camaraderie and fairness among operators. In the pilot program, due dates for exams were relaxed, and the feedback was that students, even bus operators, work best with deadlines, providing they are fair and reasonable.

\section{Teaching by Distance Education}

Initially, there was a strong desire by the BAV to implement the course as a distance education program. The association believed this would allow operators to study on their own time. Association representatives also felt that distance education would eliminate the need for rural operators to travel to the metropolitan area to attend the intensive course. Distance education was seen as more flexible and more apt to accommodate the disparity of bus operators' locations.

Distance education is the process of studying away from a regular classroom situation. Usually, it means that material is sent to students and that students receive a grade based on course projects and exams. In actuality, distance education is much more. Students must be self-disciplined and have accessibility to staff. For many people, an essential and enjoyable aspect of learning is contact with other students. Therefore, the formation of study groups is strongly encouraged; at the very least, telephone or email communication is encouraged. This type of interaction provides an opportunity to discuss the course, providing a different perspective and interpretation of study material, which is extremely important in the learning process. It also provides an opportunity for students to articulate their understanding of topic material verbally with fellow students. On the other hand, some students prefer to work on their own, either because that is their preferred study mode, or because of the business's competitive nature. To promote a sense of belonging, and to help communication between tutors and students, correspondence is posted at intervals throughout the semester. 
It is also important for the university administration to monitor enrollment and student correspondence, especially situations where a student has misplaced information or has not received essential material. For this reason, subject material is sent at the beginning of each semester, rather than when requested.

\section{Assessment}

The exam, in the form of an assignment, is provided with the printed subject material at the beginning of the course, and comprises a number of shortand long-answer questions. Except for subject 2101 (the basic course for small school bus operators), the questions are predominantly based on a case study, where operators are expected to apply their knowledge and skills to a fictitious scenario. The case study describes a family-based company, which began as a single bus operation after World War II and expanded to employ 35 people in 1996. It is designed to be a realistic scenario outlining the evolution of a business and the principle challenges (e.g., contemporary management philosophy and competitive tendering) it faces in the 21 st century.

\section{Feedback}

The fact that the grapevine is active in this industry can be an advantage as word gets around very quickly. The negative side is that misunderstanding can cause considerable anxiety among operators during the early stages of the course. It is, therefore, essential to have effective and ongoing communication with the BAV and the government.

Once operators have completed the course, they often speak positively about the experience and what they have learned.

- “... There are a few new things I am going to apply to my business as a result of completing the course."

- "... [The course] has given our operation a fixed set of guidelines to adhere to, and should promote uniform professionalism to the bus and coach industry."

- "In over 20 years of driving and operating a one-bus school tender, I have never had formal instructions except on an ad-hoc basis. The whole lot has been interesting. I understand the need for such a course and can appreciate 
its safety aspect. I feel I am far more attuned now that we have finished the course and thoroughly recommend the subject to all small operators."

- "I found all parts of the subject helpful and informative. It clarified many areas that I was not overly familiar with. I found vehicle safety requirements, driver requirements, and customer service requirements most interesting."

- "When I first perused this exam paper, I had a very negative feeling, namely due to my age and the fact that it is about 50-odd years since my last study sojourn. But as I read and became familiar with the acts and regulations, I believe I began to understand the whole purpose of the accreditation concept. As to which parts of the subject were most useful, I would have to say the whole course was most enlightening, and highlighted many regulations that were gray areas previous to my study."

- "I applaud and congratulate the people who put this course in place. It contained a wide range of interesting subjects relating to our industry. Operators will use this information to the betterment of the passenger transport industry and provide a more professional image to the public."

As anticipated, not all participants had favorable comments. A recurring complaint among operators was that the course was not always tailored to their particular and immediate needs. For example, regarding the marketing, planning, and operations subject, one question addressed preparing a tender document for a service involving a number of zones. A student commented that the question was "absolutely ridiculous for a country-based operator with a diminishing rural population. The chance of this happening is zero."

Negative comments were also received on the financial management subject. One student noted: "I strongly feel that topics 3102.3 and 3102.4 were far too 'in depth' for many operators. Many of us have accountants who are paid to deal with these subjects and I believe that these subjects, in particular, will cause a great deal of stress to many people. I suggest that this matter be very seriously considered with a view to simplifying the content."

Another noted: "I think the subject should be more focused on running a small partnership instead of a company. It should also be orientated toward costing charters." 
Some comments reflect the diversity of participants and their general attitude to the idea of having to take the courses. For example, one participant stated: "Make the subjects more user-friendly. These subjects were basically designed for a big operator, not for operators who went to school 40 years ago." In addition, one student stated: "Condense and make more user- and idiotfriendly by being more specific and less jargonistic. An awful lot of people don't want to further their education but are forced to."

Despite these adverse views, on balance, the comments could be considered reasonable, helpful, and informative. Several operators who have completed the program have taken a greater interest in its progress and have volunteered to assist in revising and updating the course in the future.

\section{Issues and Challenges}

Development of the course content and process has highlighted a number of educational issues in terms of balancing the course material toward rural rather than metropolitan operations. In addition, the course has focused on legislative problems and anomalies that have required subsequent discussion with the government. While it is easy to separate the roles of university, government, and industry in theory, it is essential that communication between the three organizations is effective.

Due to the quasi-protectionism and sociopolitical environment the industry has operated under, there are a number of inconsistencies in legislation and practice. Generally, these are small but indicate the complex nature of community service combined with commercialism. Examples include regulations concerning stopping the vehicle at a defined bus stop and the responsibilities a driver has if another vehicle is parked in the designated bus stop. Where, legally, is the driver entitled to stop the vehicle to allow passengers to alight? It is illegal for a bus driver to allow a passenger to alight anywhere other than a bus stop. There has been a case where a bus operator "rightfully" asked a school child to get off the bus for not having a valid ticket. A car struck the teenager, and the bus driver was deemed responsible, even though the bus driver was within his rights by refusing to carry a passenger without a ticket. 
Similarly the new Disability Discrimination Act requires vehicles to be accessible to disabled people, but incompatibility between vehicle design and road infrastructure (low floors and kneeling) can preclude certain operations. For example, low-floor vehicles have difficulty with speed humps and rural roads, and a concrete pad is required at stops for wheelchairs to be safely alighted. In rural areas, this is not always provided, especially where there are unsealed shoulders or no footpaths.

Scheduled passenger services in Victoria operate as franchises with payments for services made on a cost-reimbursement rather than patronage-incentive basis. With the introduction of electronic ticketing, reduced fare evasion, and reliable data collection of patronage levels, the government and operators will be able to move confidently to patronage-based payments. The contract transition is in place but the technology is not. Current cost reimbursement models mean that the more kilometers traveled, the higher the service payment, making suburban and outer-suburban routes more attractive to operators. The course currently covers market research and survey design aspects, which may be enhanced when operator profit also depends on customer numbers.

Change for any human being is difficult when imposed by an outside entity, and there is a whole profession and body of literature on change management. It is even more intimidating when accompanied by compulsory study and the reminder of possibly upsetting school days. Therefore, it is important to continue to engage members of the industry and not rely solely on the industry body, in evolving the course. Recent changes in BAV leadership have necessitated this more than would otherwise be the case. Inevitably, there are as many views as there are individuals, so it is necessary to thoroughly research the implications of proposed improvements. For example, in response to a request by operators to reduce the amount of travel (some are located 7 hours from the Melbourne metropolitan area), familiarization/introductory sessions have been held in a few country locations. An alternative was to encourage operators traveling to the introductory sessions in Melbourne to carpool using a bus. This provided an additional benefit of encouraging group discussion after the session. 


\section{Conclusions}

There are many challenges facing the bus and coach industry in Australia today. Victoria's transport management course is designed to be a step toward bringing the industry up to knowledge of best practice. The course is new and as such its long-term impacts on the sector cannot be assessed. By the end of 1999, more than 500 pass grades in individual subjects had been awarded and about 100 people had completed the entire course. Student evaluations of the program have generally commented that it is valuable, and encouragingly have been willing to provide their services to enhance the course in the future. Visible input by industry assists the credibility of the course and is strongly encouraged.

The diverse educational backgrounds of the operators means that university staff require patience in dealing with students as well as astuteness in identifying operators who are being difficult or deliberately intimidating. Because the very small number of dissidents can spark fear into unknowing operators, it is important to make a concerted effort to placate these individuals, either through the industry association or directly.

Communication between industry, government, and the university is critical in the evolution of a change such as a mandatory educational program brought about by new legislation. The familiarization sessions were an important tool for relieving fears by introducing, in person, the university staff and explaining the subject material and exam questions. The sessions have also provided the opportunity for students to network and make initial contact for study groups. Continuity of personnel during periods of major regulatory change, which takes many years, is extremely helpful in minimizing repetition and anomalies. Although the process is taxing and complex and requires perseverance, it is certainly worthwhile and necessary since the education process helps to strengthen the industry and improve service to the community.

\section{Endnotes}

1. The regulations apply to passenger vehicles with more than 12 seats (including the driver's seat).

2. In applying for accreditation, a person is also required to provide: a statement giving full details of any civil or criminal convictions under the Crimes Act or Public Transport Competition Act; a statement indicating whether the applicant has been declared bankrupt in the last five years, or has been con- 
victed of any civil offense under the relevant companies legislation; and references of good repute from two persons who have known the applicant for at least five years.

3. In addition, it was helpful to be a member of the then Bus Proprietors Association (now BAV). Membership was, and is, at the discretion of the association's board of directors. The New South Wales Department of Transport still accepts membership of the BAV as a proxy for accreditation in Victoria, though changes to this policy are expected.

4. "Significant charter" refers to charter movements other than movements during school hours for the school serviced by the operator.

\section{References}

Public Transport Safety Directorate. August 1999. Bus information. Department of Infrastructure, Victorian Government. http://www.doi.vic.gov.au/ptsd/businfo.htm.

Victorian Government. 1995. Public transport competition act. Melbourne: Government Printer for the State of Victoria.

Victorian Government. 1999. Public transport competition regulations. Melbourne: Government Printer for the State of Victoria.

\section{About the Authors}

SAMANTHA TAYLOR (sam.taylor@eng.monash.edu.au) graduated from Monash University with a civil engineering degree and a Master of Engineering Science (Research). She was program director and manager of the Transport Management Course in bus and coach operations during its development and implementation phases. In 1998, Ms. Taylor was a member of the International Advisory Committee for the Portland (Oregon) Metropolitan Area Commodity Flow Study.

KENNETH BUTTON (kbutton@gmu.edu) is professor of public policy in the Institute of Public Policy at George Mason University. Prior to this, he had been conseiller in the advisory unit to the secretary general of the Organization for Economic Cooperation and Development, Paris. At that time, he was on leave from being concurrently professor of applied economics and transport at Loughborough University and VSB Visiting Professor of Transport and the Environment at the Tinbergen Institute, Amsterdam. 